\title{
Syncope and Influenza: A Case of Bradycardia
}

Dr. Mohamad Al Farouh ${ }^{1 *}$, Dr. Irfan Shaikh ${ }^{2}$

${ }^{1}$ Specialist Internal Medicine, PHCC, Doha, Qatar

${ }^{2}$ Consultant Family Medicine, PHCC, Doha, Qatar

DOI: $10.36347 /$ sjams.2020.v08i09.042

| Received: 09.09.2020 | Accepted: 25.09.2020 | Published: 30.09.2020

*Corresponding author: Dr. Mohamad alfarouh

Abstract

Influenza is one of the commonest viral infections. It is usually self-limiting but serious complications have been reported. As the first line of contact for patients is usually the primary care physicians it is important to recognize any complications early. This case highlights how influenza patients presenting with syncope, we should consider cardiac complication as a differential.

Keywords: Syncope Influenza bradycardia.

Copyright @ 2020: This is an open-access article distributed under the terms of the Creative Commons Attribution license which permits unrestricted use, distribution, and reproduction in any medium for non-commercial use (NonCommercial, or CC-BY-NC) provided the original author and source are credited.

\section{INTRODUCTION}

There is relationship between Influenza and cardiac disease is known and complex. Although mostly Influenza is limited to respiratory system but carditis and pericarditis are well known complications [1-5]. QT prolongation has been reported to be caused by cardiac and non-cardiac medications. Macrolides including Clarithromycin are one of them. This can be fatal though rarely [6]. It may be difficult to distinguish complication of Influenza from primary cardiac problem especially during the Influenza season [5].

Syncope can be caused by various causes. It is important to recognize early potential cardiac complication of Influenza. This can also benefit differentiating primary cardiac cause of syncope.

\section{Case Presentation}

A case of 32-year-old male with history of fever, cough and sore throat for 2 days. He was seen by primary care physician and started on clarithromycin, paracetamol and dextromethorphan.

Next day he attended emergency clinic with history of loss of consciousness while sitting with friends with urinary incontinence. He was referred to Hospital for further investigations.

While the ECG as being done in ER, he became unresponsive again, his HR dropped to 20 on
ECG monitor (Figure1), the technician could not feel carotid pulse, CPR was started and by the time one cycle was completed he regained consciousness. After this episode he was fully conscious, HR was 120 regular (Figure 2), RBS 6. He denied any symptoms of chest pain, palpitations, and shortness of breath or feeling dizzy prior to the episode.

$\mathrm{He}$ was admitted to CCU for further observation and considers pacing. His CT head, echocardiogram 48 hours Holter monitor, blood tests including FBC, CRP, Ferritin, Magnesium, Calcium, $\mathrm{U}+\mathrm{E}$ and chest $\mathrm{x}$-ray were normal. ALT was borderline raised. His swabs were positive for H1N1 Influenza

During his stay at hospital he had no further episodes of syncope or bradycardia. The plan for pacemaker was cancelled.

The working diagnosis was $\mathrm{H} 1 \mathrm{~N} 1$ induced bradycardia. He was followed up in outpatient department 2 weeks after discharge and was stable and asymptomatic

\section{Differential diagnosis}

1. Seizure

2. Side effect of Clarithromycin

\section{Outcome and Follow-Up}

Patient improved with conservative management and discharged from hospital 


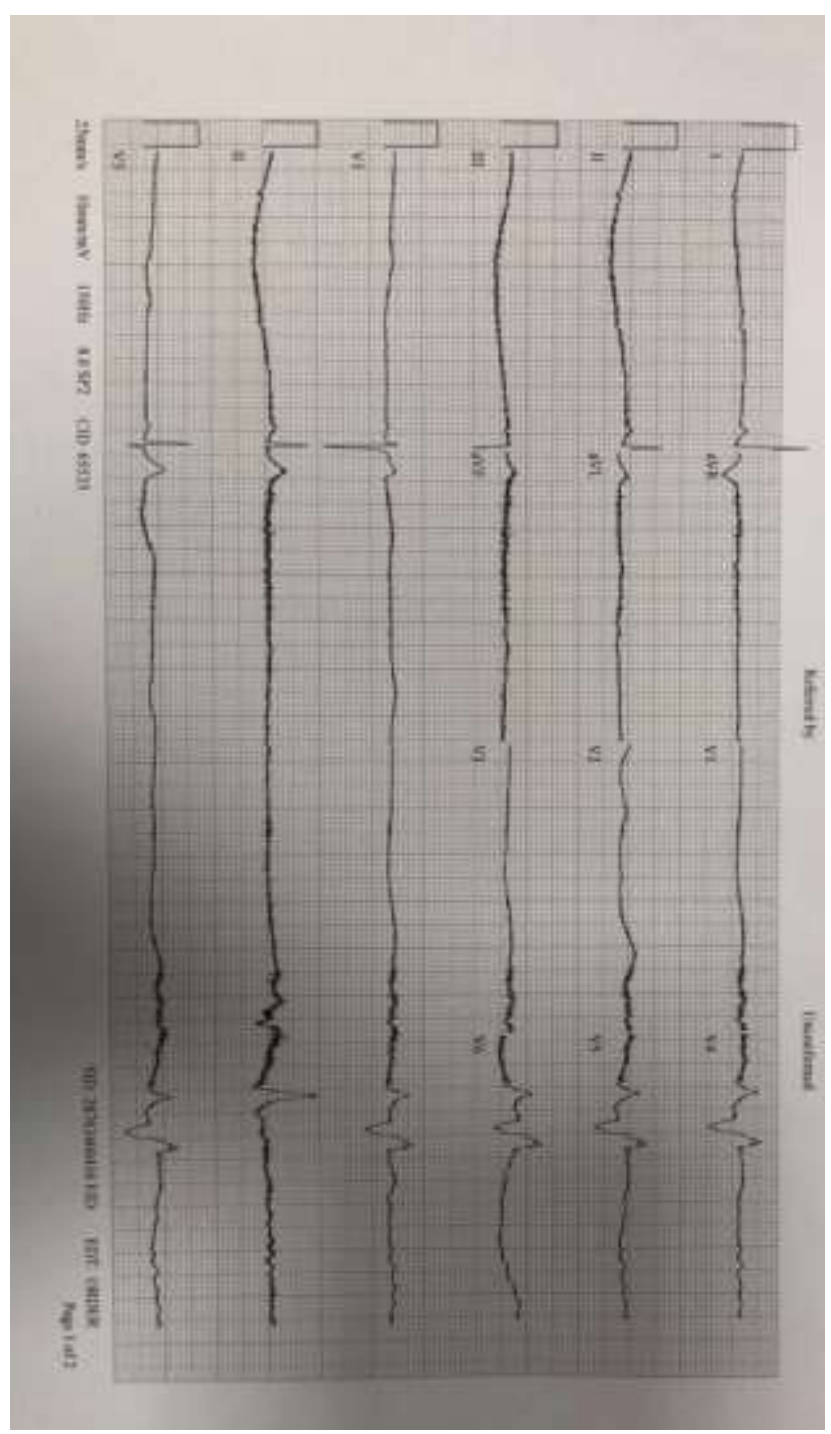

Fig-1

\section{DISCUSSION}

Influenza is common condition presenting to primary care physicians [7]. This case having 2 episodes of syncope and documented bradycardia is unique as it is usually difficult to document the bradycardia and it is assumed to be the cause of syncope. Moreover, the history of incontinence and that patient received macrolide antibiotic would have altered the diagnosis had the bradycardia episode not been witnessed and documented.

Since primary care physicians are at the forefront in the diagnosis and treatment of influenza patients, awareness that influenza can have a greater role in triggering cardiac events is essential and lifesaving especially in unvaccinated patients

\section{REFERENCES}

1. Mamas MA, Fraser D, Neyses L. Cardiovascular manifestations associated with influenza virus infection. Int J Cardiol. 2008; 130:304-9

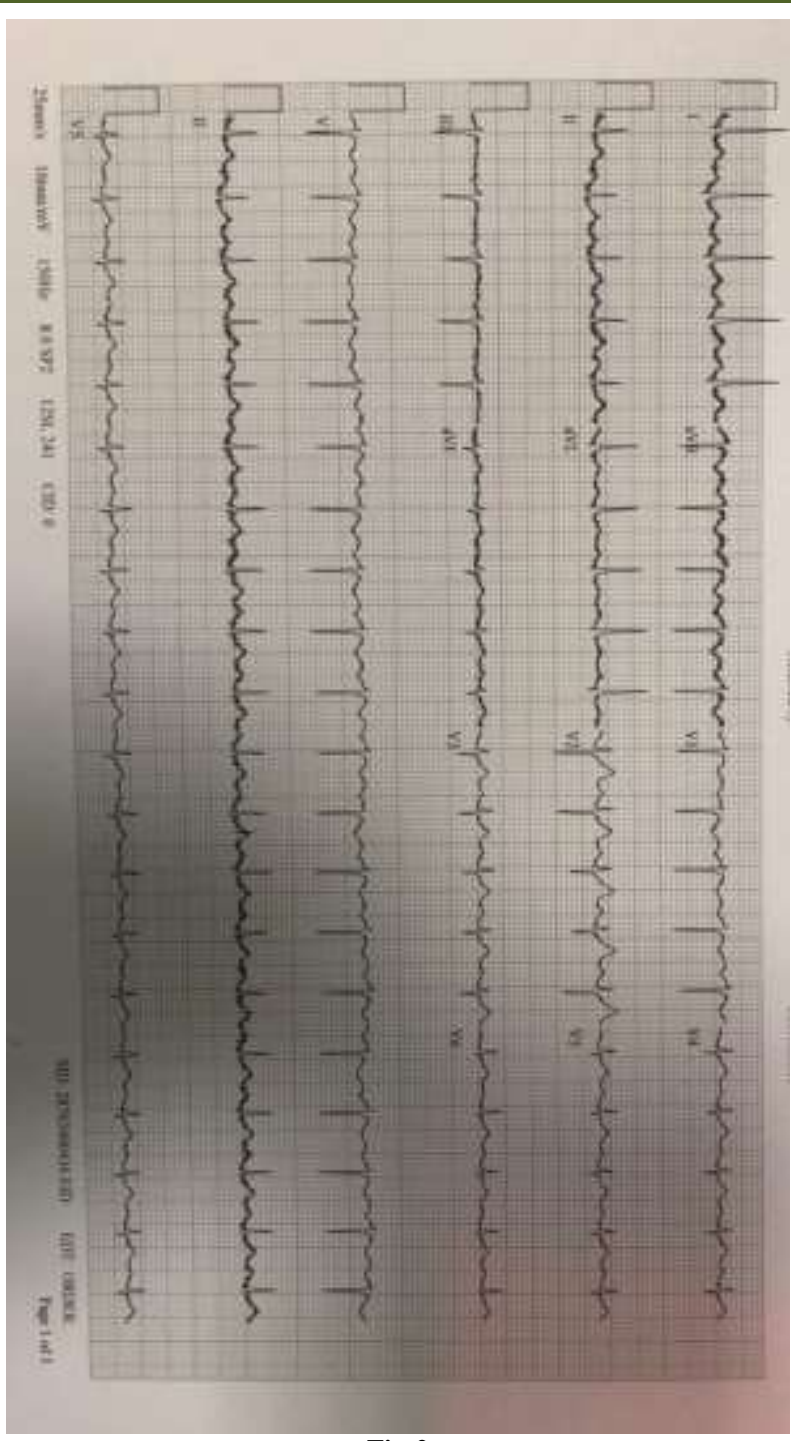

Fig-2

2. Jeyanathan $\mathrm{T}$, Overgaard $\mathrm{C}$ and McGeer A. "Cardiac complications of influenza infection in 3 adults," Canadian Medical Association Journal. 2013; 185(7): 581-584.

3. Rothberg MB, Haessler SD and Brown RB. "Complications of Viral Influenza," American Journal of Medicine. 2008, 121(4): 258-264.

4. Estabragh ZR and Mamas MA. "The cardiovascular manifestations of influenza: A systematic review," International Journal of Cardiology. 2013, 167(6): 2397-2403.

5. Steinberg C and Chakrabarti S. "H1N1-associated sinus node dysfunction," Heart Asia. 2015; 7(1): 16-17.

6. Chang, Nai-Lun, Shah, Priank. American Journal of Therapeutics: May/June. 2016; 23(3): e955-e956

7. Centers for Disease Control and Prevention, "CDC - Seasonal Influenza (Flu). Centers for Disease Control and Prevention," http://www.cdc.gov/flu/ 